\title{
Effect of Moisture Stress Conditions on Yield and Yield Attributing Characters of Four Cowpea (Vigna unguiculata L. Walp) Genotypes
}

\author{
P.B. Kardile ${ }^{1 *}$, K.N. Dahatonde ${ }^{2}$, M.M. Burondkar ${ }^{1}$ and S.G. Bhave ${ }^{1}$

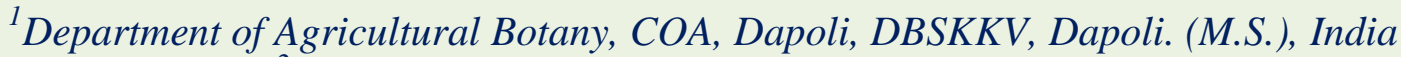 \\ ${ }^{2}$ Department of Horticulture, MPKV, Rahuri, India \\ *Corresponding author $\backslash$
}

\section{A B S T R A C T}

\section{Keywords}

Moisture, Stress, generative growth, Sink capacity, Grain yield per plant

Article Info

Accepted:

26 March 2018

Available Online:

10 May 2018
Present research was conducted to assess the performance of four cowpea genotypes (Fodder cowpea-1, konkan sadabahar, ACP-109, PCP-9702-1) under moisture stress conditions, at research farm department of Agricultural Botany COA, Dapoli, DBSKKV, Dapoli (M.S.). This research was carried Out to investigate the component traits responsible for developmental plasticity and mechanism of sustaining yield levels in water deficit conditions with support of growth analysis biochemical physiological parameters yield and yield contributing characters study studies on yield contributing characters viz., day to $50 \%$ flowering day to maturity, number of pods per plant, length of pod number of grains per pod,100 grain weight, grain yield per plant and grain yield per hectare found to be influenced significantly by different water stress treatment in cow pea genotypes. Changes in above mentioned parameters showed that fodder cow pea-1 and kokan sadabahar both varieties are much tolerant to water stress compared to ACP-109 and PCP-

\section{Introduction}

Pulses have been recognized as a major source of vegetable protein with needed minerals and vitamins. They play a vital role in maintaining soil fertility by fixing atmospheric nitrogen. Among pulses, Cowpea (Vigna unguiculata (L.) Walp.) is most important legume crop in Asia, Africa, Australia and U.S.A. Water stress is the most common adverse situation which affects the production of agricultural crops all over the world. Konkan region of Maharashtra represents a typical contrasting situation of ample availability of water through assured and heavy monsoon rainfall (average $3,500 \mathrm{~mm}$ ) occurring rigidly only during June to October on one hand and everincreasing terminal water stress caused by a high infiltration rate $(4.4 \mathrm{~cm} / \mathrm{hr})$, poor water holding capacity (27.15 to 30.30 per cent at field capacity and 16.60 to 18.10 per cent at P.W.P. (Dongale et al., 1987) on the other hand.

Practically no rainfall from October to May accentuates the strength of water stress which limits the yield of field crops, commonly the grain legumes viz., cowpea, horsegram, lablab bean etc. which are grown on stored soil moisture in rice fallows during post monsoon season. It is well known fact that cowpea has greater developmental plasticity than some of 
the cultivated legumes which imparts it drought tolerance. The present study was studied to reveal the component traits responsible for developmental plasticity and mechanism of sustaining yield levels in water deficit conditions with support of growth analysis and biochemical investigation.

To investigate the impact of moisture stress on morpho-physiological traits of cowpea genotypes. To study the impact of moisture stress on various growth parameters and biochemical parameters of cowpea genotypes. To find out moisture stress tolerant, high yielding and high biomass producing genotypes of cowpea.

\section{Materials and Methods}

The experimental material for the study consisted of 4 genotypes of cowpea. The seeds of four cowpea genotypes were collected from Research farm, Department of Agril. Botany, College of Agriculture, Dapoli (M.S.). The experiment comprised of 4 genotypes of cowpea laid out in split plot Design with three replications provided with three different moisture stress levels. The experiment was conducted in Split Plot Design with three replications. The stress treatments were imposed at three different levels. In first moisture stress treatment, crop was grown on control with zero stress from sowing to maturity. In second moisture stress treatment, cowpea crop was subjected to moisture stress from pre flowering to maturity, i.e. with helding irrigations from $40 \mathrm{DAS}$; and third stress treatment was taken as cowpea crop was grown on available residual soil moisture from sowing to the maturity.

\section{Results and Discussion}

The results obtained in the present investigation are presented under the following head.
Generative growth and sink capacity four Cowpea (Vigna unguiculata L. Walp.) Genotypes

Study of yield and its components indicated significant differences amongst the 4 genotypes under different intensities of water stress. From the present investigation it is revealed that, the genotype Konkan sadabahar was earliest to flower and showed less reduction for days to flower under severe $(8.78 \%)$ stress condition, followed by ACP109 which showed $(10.06 \%)$ less reduction than two other genotypes studied, while genotype ACP-109 showed less (6.72 \%) reduction in days to maturity under severe stress condition, followed by fodder cowpea-1 which showed $(7.5 \%)$ less reduction than two other genotypes studied, indicating the better performance of these genotypes for reproductive attributes under moisture stress conditions. In the present investigation, the grain yield per plant ranged from $(0.29 \mathrm{~g})$ to $(7.07 \mathrm{~g})$, the lowest and highest being in genotype PCP-9702-1 and fodder cowpea-1, respectively.

The genotype Konkan sadabahar was earliest to flower and showed less reduction for days to flower under severe $(8.78 \%)$ stress condition, followed by ACP-109 which showed $(10.06 \%)$ less reduction than two other genotypes studied, while genotype ACP109 showed less $(6.72 \%)$ reduction in days to maturity under severe stress condition, followed by fodder cowpea-1 which showed $(7.5 \%)$ less reduction than two other genotypes studied, indicating the better performance of these genotypes for reproductive attributes under moisture stress conditions. On an average, 25 to 30 days were taken by the genotypes from flowering to maturity. The variation in days to flowering and maturity in cowpea crop was also reported by Turk et al., (1980) Patil (1989), Parab (1991) and Shinde (1998). 


\section{Grain yield}

Grain yield is the economic part of the total dry matter. This is the end product of the plants life cycle and it is of much interest to mankind. Yield is a compound character and is a sum total of the contribution made by a number of physiological characters.

It is an ultimate product of the action and interaction of a number of component plant characters. To the plant physiologist, it is net economic gain from the source and sink capacity. In the present investigation, the grain yield per plant ranged from ranged from $(0.29$ g) to $(7.07 \mathrm{~g})$, the lowest and highest being in genotype PCP-9702-1 and fodder cowpea-1, respectively. Genotype konkan sadabahar, followed by fodder cowpea-1, showed less reduction $(64.79 \%)$ and $(69.22 \%)$ in grain yield per plant under severe stress condition than two other genotypes studied, indicating the ability of the genotype to tolerate the drought condition. This indicated the existence of a considerable amount of variation for this character amongst the genotypes studied. The varietal differences for grain yield per plant in cowpea and pulse crops were also reported by, Naidu et al., (2001), Reddy et.al., (2001), Rao et al., (2003) Elzanloo et al., (2005) Abayomi et al., (2007) Abdelshkoor et al., (2010) and Ahmed et al., (2010).

Table.1 (a) Influence of various degrees of water stress on yield and yield contributing characters of cowpea genotypes

\begin{tabular}{|c|c|c|c|c|c|c|}
\hline \multirow[t]{2}{*}{ Genotypes } & \multicolumn{4}{|c|}{ Degrees of water stress } & \multirow[t]{2}{*}{$\mathrm{SE} \pm$} & \multirow[t]{2}{*}{ CD at $5 \%$} \\
\hline & Zero & Strong & Severe & Mean & & \\
\hline \multicolumn{7}{|c|}{ Days to $50 \%$ flowering } \\
\hline Fodder Cowpea -1 & 55.79 & 53.67 & 50.00 & 53.15 & V. 0.085 & 0.248 \\
\hline PCP 9702-1 & 59.67 & 57.00 & 53.67 & 56.78 & S. 0.064 & 0.249 \\
\hline Konkan sadabahar & 49.33 & 46.78 & 45.00 & 47.04 & \multirow{3}{*}{$\begin{array}{l}\mathrm{S} \times \mathrm{V} \\
0.255\end{array}$} & \multirow{3}{*}{0.805} \\
\hline ACP -109 & 54.19 & 51.00 & 48.67 & 51.29 & & \\
\hline Mean & 54.75 & 52.11 & 49.33 & 52.06 & & \\
\hline \multicolumn{7}{|c|}{ Days to maturity } \\
\hline Fodder Cowpea -1 & 79.52 & 76.97 & 73.56 & 76.68 & V. 0.134 & 0.391 \\
\hline PCP 9702-1 & 86.73 & 80.33 & 77.33 & 81.46 & S. 0.096 & 0.371 \\
\hline Konkan sadabahar & 67.67 & 63.67 & 61.33 & 64.22 & \multirow{3}{*}{$\begin{array}{l}\mathrm{S} \times \mathrm{V} \\
0.402\end{array}$} & \multirow{3}{*}{0.402} \\
\hline ACP -109 & 81.16 & 78.33 & 75.71 & 78.40 & & \\
\hline Mean & 78.77 & 74.83 & 71.98 & 75.19 & & \\
\hline \multicolumn{7}{|c|}{ No. of pods per plant } \\
\hline Fodder Cowpea -1 & 8.74 & 5.15 & 2.39 & 5.43 & V. 0.062 & 0.180 \\
\hline PCP 9702-1 & 5.86 & 3.67 & 2.11 & 3.88 & S. 0.118 & 0.452 \\
\hline Konkan sadabahar & 7.51 & 4.44 & 2.33 & 4.76 & \multirow{3}{*}{$\begin{array}{l}\mathrm{S} \times \mathrm{V} \\
0.185\end{array}$} & \multirow{3}{*}{0.657} \\
\hline ACP -109 & 8.26 & 4.89 & 1.67 & 4.94 & & \\
\hline Mean & 7.59 & 4.54 & 2.12 & 4.75 & & \\
\hline
\end{tabular}


Table.1 (b) Influence of various degrees of water stress on yield and yield contributing characters of cowpea genotypes

\begin{tabular}{|c|c|c|c|c|c|c|}
\hline \multicolumn{7}{|c|}{ Pod length (cm) } \\
\hline Fodder Cowpea -1 & 16.74 & 14.60 & 10.19 & 13.84 & V. 0.079 & 0.232 \\
\hline PCP 9702-1 & 12.55 & 10.33 & 7.67 & 10.18 & S. 0.032 & 0.123 \\
\hline Konkan sadabahar & 11.38 & 10.67 & 7.00 & 9.68 & \multirow{3}{*}{$\begin{array}{c}\mathrm{S} \times \mathrm{V} \\
0.238\end{array}$} & \multirow{3}{*}{0.715} \\
\hline ACP -109 & 13.81 & 11.33 & 8.67 & 11.27 & & \\
\hline Mean & 13.62 & 11.73 & 8.38 & 11.24 & & \\
\hline \multicolumn{7}{|c|}{ No. of grains per pod } \\
\hline Fodder Cowpea -1 & 14.67 & 9.33 & 6.67 & 10.22 & V. 0.102 & 0.299 \\
\hline PCP-9701-2 & 11.44 & 6.92 & 4.89 & 7.75 & S. 0.070 & 0.268 \\
\hline Konkan sadabahar & 12.55 & 7.61 & 5.50 & 8.55 & \multirow{3}{*}{$\begin{array}{c}\mathrm{S} \times \mathrm{V} \\
0.307\end{array}$} & \multirow{3}{*}{0.957} \\
\hline ACP -109 & 12.67 & 7.67 & 5.49 & 8.61 & & \\
\hline Mean & 12.83 & 7.88 & 5.63 & 8.78 & & \\
\hline \multicolumn{7}{|c|}{ Grain yield per plant (g) } \\
\hline Fodder Cowpea -1 & 7.07 & 2.21 & 0.61 & 3.30 & V. 0.035 & 0.101 \\
\hline PCP 9702-1 & 3.30 & 1.04 & 0.29 & 1.55 & S. 0.061 & 0.233 \\
\hline Konkan sadabahar & 4.99 & 1.48 & 0.46 & 2.31 & \multirow{3}{*}{$\begin{array}{c}\mathrm{S} \times \mathrm{V} \\
0.104\end{array}$} & \multirow{3}{*}{0.365} \\
\hline ACP -109 & 5.34 & 1.55 & 0.32 & 2.40 & & \\
\hline Mean & 5.18 & 1.57 & 0.42 & 2.39 & & \\
\hline
\end{tabular}

Fig.1. Effect of water stress on grain yield/plant (g) of four cowpea genotypes

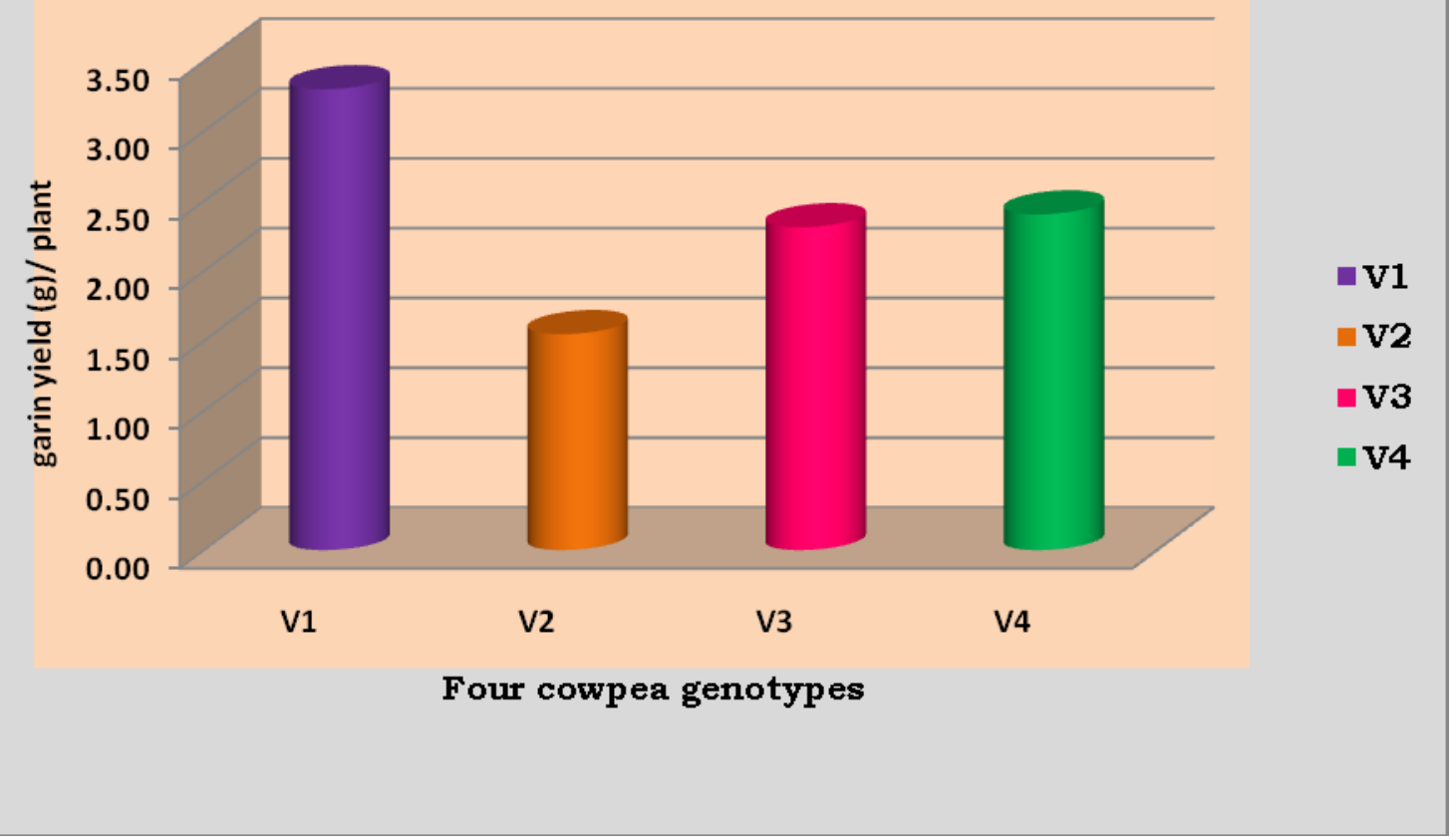




\section{Harvest Index (H.I.)}

Although, both the grain and biomass yield are important, grain yield is more important than biomass yield and hence, it is necessary to study relationship of grain to biomass. This is effectively done by working harvest index. Harvest index is the percentage of biological yield, represented by economic yield. Donald (1962) defined the harvest index as, "the ratio of grain weight to the total dry weight of above ground parts at maturity of the crop. Partitioning of dry matter into economic and non-economic parts is interest to plant scientist, because yield in any crop depends upon its capacity to produce dry matter and its efficient partitioning between economic and non-economic parts. Harvest index helps in knowing how much of the total dry matter is converted into economic part. Higher this conversion, higher will be harvest index and hence, this would help in designing an ideal plant type where more portion of the total dry matter is converted into economic parts.

In the present investigation, it was observed that the harvest index ranged from 1.60 to 13.51 per cent. This indicated the existence of variability amongst the genotypes studied. Genotypes Konkan sadabahar and PCP-97021 showed less reduction $52.15 \%$ and $59.29 \%$ in terms of H.I. under severe stressed conditions than two other genotypes studied indicating the ability of the genotype to move with stand under water stress condition. Genotype konkan sadabahar, followed by fodder cowpea-1, showed less reduction $(64.79 \%)$ and $(69.22 \%)$ in grain yield per plant under severe stress condition than two other genotypes studied. Plants under zero stressed condition recorded higher harvest index (62.83 and 78.73) per cent over plants under strong stressed and severe stressed conditions respectively. The two physiological processes that are closest to final yield expression are net accumulation of photosynthates and the partitioning of photosynthates between grain and other plant organs. This was because of the different in total dry-matter production and hence, it appears that instead of considering the harvest index alone, it would be worthwhile to consider it along with the total dry matter production. Therefore, in any crop improvement programme an improvement both in biological yield and harvest index would alone cause enhancement in the economic yield. The varietal difference for harvest index in cowpea has also been reported by Patil (1989), Parab (1991) Shinde (1998) Abidoye (2004) and Abayomi et al., (2009). Genotypes Konkan sadabahar and PCP-9702-1 showed less reduction $(52.15 \%)$ and $(59.29 \%)$, respectively in terms of H.I. under severe stressed conditions than all other genotypes studied, indicating the ability of the genotype to maintain good partioning ability under water stress condition.

In conclusion, it is to be stated that, a wide range of variability existed for the different growth and yield parameters among 4 cowpea genotypes. Among four genotypes of cowpea studied, under three different water stress conditions genotypes, fodder cowpea-1 followed by konkan sadabahar recorded high yield under severe stressed condition, owing to their higher efficiency to accumulate more dry matter, less reduction in plant height, maintainance of photosynthetically active apparatus, less transpirational water loss, higher proline accumulation, chlorophyll content and relative water content, respectively in terms of H.I. under severe stressed conditions than all other genotypes studied, indicating the ability of the genotype to maintain good partioning ability under water stress condition. This showed attributed to better yield. This information may be helpful for better understanding of concepts of critical stages of vegetative and reproductive growth and its applications to 
the effect of drought on various aspects of growth and yield of cowpea. It can be employed for crop improvement programme as well as efficient management practices for cowpea production in drought prone conditions.

\section{References}

Abayomi Y.A. and T.O. Abidoye (2009): Evaluation of cowpea genotypes for soil moisture stress tolerance under screen house conditions. African Journal of Plant Science Vol. 3 (10), pp. 229-237, October, 2009

Abidoye T.O. and Abayomi Y.A. and (2009): Evaluation of cowpea genotypes for soil moisture stress tolerance under screen house conditions. African Journal of Plant Science Vol. 3 (10), pp. 229-237, October, 2009

Ahmed Faisal Elgasim and Abdel Shakoor H. Suliman (2010). Effect of water stress applied at different stages of growth on seed yield and water-use efficiency of Cowpea. Agriculture and biology journal of North America: Online: 2151-7525.

Elzanloo, A.H., Zeinalio, A.H. Hoseinzadeh., N.M. Oseini and M. Sabokdast (2005).
Performance of commercial soybean var. under water stress condition at the late reproductive stage. Iranian J.Agril. Sci. 36(4)

Parab, B. (1991). Effect of different levels of potassium nutrition on growth and yield of cowpea (Vigna unguiculata) variety VCM-8 under the moisture stress at different phases of growth. Thesis submitted for M.Sc (Agri.) programme to KKV, Dapoli (1991) pp.18.

Patil, R.B. (1989). Effect of moisture stress on growth and yield of cowpea (Vigna unguiculata $\mathrm{L}$. walp.). Thesis submitted for M.Sc. (Agri.) programme to K.K.V. Dapoli, pp.22.

Rao, V., P.C. Nautiyal, and Y.C. Joshi. (2003). Physiological analysis of drought resistance and yield in three legumes. Trop. Agric. (Trinidad), 67: 290-296.

Reddy, T.V.B and Prakasrao, J.S. (2001). Physiological and biochemical evaluation of groundnut cultivars differing in drought tolerance.

Shinde A.K. (1998), Alleviation of drought in five legumes. A Ph.D. thesis submitted to DBSKKV, Dapoli (M.S.)

\section{How to cite this article:}

Kardile, P.B., K.N. Dahatonde, M.M. Burondkar and Bhave, S.G. 2018. Effect of Moisture Stress Conditions on Yield and Yield Attributing Characters of Four Cowpea (Vigna unguiculata L. Walp) Genotypes. Int.J.Curr.Microbiol.App.Sci. 7(05): 3688-3693. doi: https://doi.org/10.20546/ijcmas.2018.705.426 